\title{
Crítica de la historia, política emancipatoria y moralidades postmodernas: la obra de Keith Jenkins ${ }^{1}$
}

\section{Critique of history, emancipatory policy and postmodern moralities: the work of Keith Jenkins}

\author{
Aitor Manuel Bolaños de Miguel \\ UNIR
}

Resumen. Keith Jenkins es uno de los pensadores postmodernos más conocidos en el ámbito de la reflexión historiográfica occidental. Sin duda, junto con Hayden White y Frank R. Ankersmit, conforma el trío más influyente de la corriente historiográfica postmoderna. Vamos a exponer en este trabajo la evolución de la obra de Jenkins desde lo que llamamos una crítica radical a la historiografía académica hasta lo que podemos considerar una auténtica aversión a la forma de aprehensión del pasado, tal y como es concebido, practicado y usado en la actualidad. Hemos dividido en dos apartados nuestra exposición para dar cabida así a estos dos momentos clave en el desarrollo de su teoría y de su obra: el momento difusor de la crítica postmoderna a la historiografía y el momento de la expulsión de la historiografía de cualquier proyecto político emancipador.

Palabras clave: Keith Jenkins, Postmodernidad, Historiografía, Crítica Política.

Keith Jenkins es uno de los pensadores postmodernos más conocidos en el ámbito de la reflexión historiográfica occidental de finales del siglo XX y comienzos del XXI. Sin duda, junto con Hayden White $^{2}$ y Frank R. Ankersmit ${ }^{3}$ - los dos «expertos
ABSTRACT. Keith Jenkins is one of the most famous postmodern thinkers in the field of Western historiographical reflection. Without doubt, along with Hayden White and Frank R. Ankersmit, constitute the most influential trio of current postmodern historiography. We will present in this paper the evolution of Jenkins' work from what we may call a radical critique of academic historiography to what we consider a real dislike to the form of thinking about the past, as it is conceived, practiced and used nowadays. We divided this article in two sections to accommodate our insight to these two key moments in the development of his theory and his work: the moment of the diffusion of postmodern critique to historiography and the time of the expulsion of the historiography of any emancipated political project.

Key words: Keith Jenkins, Postmodernism, Historiography, Political Criticism.

en demolición» de la historia con minúscula, como los llama el propio Jenkins ${ }^{4}$-, conforma el trío más influyente de la corriente historiográfica postmoderna ${ }^{5}$.

No obstante, ninguno de los tres puede ser comparado con los otros dos en 
términos absolutos, ya que, a un textualismo ${ }^{6}$ constructivista ${ }^{7}$ aceptado por todos, cada uno añade de su propia cosecha elementos dispares, los cuales, en algunas ocasiones, se complementan $\mathrm{y}$, en otras, se contradicen. Así, por ejemplo, Hayden White levanta su edificio filosófico sobre una profunda preocupación moral derivada del humanismo existencialista ${ }^{8}$-algo que, por otro lado, podría encontrarse en la obra de Jenkins pero que, sin embargo, no aparece en la de Ankersmit-, un humanismo existencialista que no es incompatible con una clara ascendencia marxista ${ }^{9}$, todo lo cual podemos también observar en el designio crítico de la obra de Jenkins ${ }^{10}$. Ankersmit, en segundo lugar, inspirado por una concepción pesimista de la naturaleza humana, consuma una defensa de la capacidad representativa pero sustitutiva de la historiografía — en la estela de su admirado Arthur Danto- complementada con una reevaluación de la experiencia ${ }^{11}$. Por último, Keith Jenkins desarrolla su crítica de las metanarrativas y de la historiografía académica - las micronarrativas - , hasta el punto de encontrar un argumento radical, como veremos, contra la necesidad de seguir representando el pasado de estas maneras. Los tres autores, por otro lado, mantienen una apuesta decidida por la accesibilidad de sus argumentos, por la claridad estilística y por la sencillez de sus exposiciones críticas. En definitiva, por un espíritu didáctico que no está reñido con la profundidad ni con la rigurosidad. Sin embargo, es Keith Jenkins el más pedagógico de los tres, por intenciones y por resultados ${ }^{12}$. En este sentido, la circulación de su obra está fuera de toda duda.

Además de la importancia de su obra por el número de lectores, interlocutores y debates mantenidos ${ }^{13}$, la labor de Jenkins es significativa por otros dos motivos. En primer lugar, por haber supuesto uno de los intentos de mayor calado en la divulgación de la perspectiva postmoderna, en particular sobre la reflexión historiográfica, lo que puede ser comprobado por el éxito de su edición The Postmodern History Reader ${ }^{14}$, o por la acogida de su The Nature of History Reader, editado en colaboración con Alun Munslow - quien es, por cierto, un ejemplar compañero en su cruzada postmoderna 15 Pero, en segundo lugar, la obra de Jenkins es importante también por haber supuesto un auténtico fenómeno de ventas en el reducidísimo mercado de las producciones culturales universitarias. El número de ejemplares vendidos de algunos de sus libros - en concreto, de Rethinking History, de 1991- ofrecen un innegable argumento en la defensa de la popularización de sus textos y en la divulgación de sus argumentos, por lo menos en el ámbito anglosajón.

Pues bien, una vez presentadas estas cuestiones, vamos a exponer en este trabajo la evolución de la obra de Jenkins desde lo que llamamos una crítica radical a la historiografía académica — tanto a la burguesa como a la marxista-, hasta lo que podemos considerar una auténtica aversión a la forma de aprehensión del pasado, tal y como es concebido, practicado y usado en la actualidad ${ }^{16}$. Hemos dividido en dos apartados nuestra exposición para dar cabida así a estos dos momentos clave en el desarrollo de su teoría y de su obra: el momento difusor de la crítica postmoderna a la historiografía profesional - una vez consumada la crítica a las metanarrativas ${ }^{17}$ — y el momento de la expulsión de la historiografía - incluida la historiografía postmoderna- de cualquier proyecto político emancipador. Escepticismo epistemológico y relativismo moral, por tanto. La matriz que une a ambos momentos de su obra es la reflexión filosófica sobre el lenguaje, el discurso y las ideologías ${ }^{18}$, 
una reflexión que siempre ha sido desplegada con un evidente propósito crítico y emancipador, sobre la base de un radicalismo que no esconde su inspiración marxista.

\section{Escepticismo: repensar la historia criticando sus presupuestos, métodos $y$ resultados}

Conviene registrar algunos puntos fundamentales en relación con el postmodernismo para poder examinar la obra de Jenkins con más claridad. En los siguientes párrafos de este apartado ofreceremos una representación de las principales características de este fenómeno ${ }^{19}$.

El postmodernismo es un conjunto de tendencias intelectuales que denuncian la naturaleza constructiva e ideológica de nuestros intentos por conocer «el mundo», «la realidad». Ésta es la conexión fundamental de la postmodernidad con el llamado linguistic turn, que es uno de los componentes del fenómeno postmoderno ${ }^{20}$, junto con el postestructuralismo, la deconstrucción o el pragmatismo ${ }^{21}$. La premisa clave de esta posición consiste en que el lenguaje no solamente describe o explica la realidad sino que también la construye: de hecho, urbaniza «nuestra» realidad humana. Así, no «descubrimos» el mundo, sino que lo «construimos» a través del lenguaje. El mundo está ahí afuera, sin duda, pero no así la verdad $^{22}$, que es un efecto de nuestros discursos en la medida en que los intentamos hacer corresponder con la realidad. Por eso, autores como Nietzsche, Wittgenstein o Derrida consideran que «la verdad» es, en el mejor de los casos, un producto de nuestro discurso y éste no se somete a los dictados de la realidad. Precisamente, Jenkins comparte la visión de Rorty de que mientras el mundo está «ahí afuera» la verdad no, ya que el significado y la verdad están en los enunciados y éstos no están «ahí afuera». Además, «la verdad» se considera parte de una ecuación en la que también figura el poder. Así, el conocimiento sería un producto de la relación entre la verdad y el poder, es decir, lo que el poder considera como verdad. Contra esto, se proponen dos ideas: la idea de que la verdad es inaccesible y, además, relativa al contexto en que se produce y la idea de la verdad como consenso intersubjetivo: es verdad lo que para «nosotros» es válido y útil como tal, y no vale para todos los individuos ni para todas las sociedades. Por todo ello, el postmodernismo denuncia la supuesta y, a la postre, falsa imparcialidad, objetividad y neutralidad de las ciencias, tanto naturales como sociales: el conocimiento siempre depende del contexto social, de los intereses del presente, de sus deseos; siempre es hecho por alguien y para alguien. Es, en el fondo, una función del discurso, de la ideología y, por tanto, del poder, que es quien decide qué es verdad y qué no. Por eso, el postmodernismo entiende que debemos ser conscientes y hacer públicos los intereses y los propósitos de nuestras acciones e investigaciones, tal y como demandan autores como Kuhn, Feyerabend, Lakatos o Hacking. El postmodernismo, al hacernos más conscientes y reflexivos, nos conmina a ser más responsables e, incluso, a hacernos responsables de las consecuencias no intencionadas —en el sentido hegeliano- de nuestras acciones $\mathrm{y}$, por supuesto, de nuestros discursos y textos. Por otro lado, no hay un único método válido, general y absoluto. Se apuesta por la fusión, la interdisciplinariedad, la transdisciplinariedad, la transversalidad, la mezcla, el experimento; en contra de la rigidez de las disciplinas y de la organización del conocimiento científico moderno.

Todas estas características tienen relación con la crítica de las metanarrativas y con la crítica de los puntales del pensa- 
miento moderno occidental, especialmente del metafísico. Se ponen en duda las filosofías del progreso, la idea de que el ser humano y las sociedades humanas progresan, pero también los metadiscursos emancipadores del marxismo, del comunismo y de otros movimientos mesiánicos. Existe, en suma, una poderosa incredulidad ante los grandes relatos, liberales, científicos, marxistas, utópicos, del capitalismo, etc. La crisis de la metafísica y, con ella - como apunta Vattimo- - la caída de la «centralidad y de la hegemonía política de Occidente, ha liberado culturas y visiones del mundo múltiples» ${ }^{23}$, que acompaña a una proliferación de la historia y, actualmente, de la memoria ${ }^{24}$. Pero existe también una creciente incredulidad ante los microrrelatos (las «historias» escritas por los historiadores): éstos — se considera- están al servicio del Estado Nación, de los nacionalismos periféricos - ahora- y de la construcción de sus respectivas identidades, en la misma medida en que la historiografía medieval estaba íntimamente relacionada con la Iglesia ${ }^{25}$. Responden, por tanto, a intereses institucionales, estatales y corporativos. Por su parte, el postmodernista típico, como escribe Jenkins, es relativista y afirma que el pasado ya no existe: por tanto, es, como tal, sublime, carente de esencia, no teleológico, por lo que cualquier intento de apropiarnos de él constituye una unidad heurística que es, «con toda claridad, "ficticia"» 26.

Como ha resumido Cristina Godoy, «la denominada postmodernidad se asienta sobre el agotamiento de las ideas de "razón" y "progreso", ideas fuerza que dominaron la visión del mundo de la modernidad. [...] En la segunda mitad del siglo Xx, el arte se ha resignificado, la novela ha muerto y las humanidades han decapitado las certezas teóricas sobre las que se habían afianzado durante un siglo de desarrollo científico» ${ }^{27}$. El tipo de reflexión postmoderna que sostiene Jenkins, a mitad de camino entre un antifundacionalismo (o antiuniversalismo) militante, un escepticismo abierto y un relativismo integrador ${ }^{28}$, tiene en frente a conservadores, más o menos liberales - como Gertrude Gimmelfarb, Perez Zagorin, Geoffrey Elton, Keith Windschuttle, entre otros-, y a críticos de izquierda - como Fredric Jameson, Terry Eagleton, Christopher Norris ${ }^{29}$ o Alex Callinicos. Es verdad, afirma Jenkins, que la postmodernidad y el postmodernismo han surgido, en parte, de las exigencias del capitalismo contemporáneo. El capitalismo tardío, como apunta Jameson, es culturalmente postmodernista, pero sólo contingentemente postmodernista, ya que el postmodernismo no es propiedad del capital, no le pertenece, al menos no de una forma esencial. Por el contrario, lo que el postmodernismo augura es la entrada de un atisbo de novedad en nuestro mundo, un ápice de novedad que, de forma constructiva, puede ayudarnos a mantener vivo el pensamiento crítico y emancipatorio que ha sido desterrado de la educación y de las universidades. «Porque es posible, como mínimo, que las críticas y los imaginarios postmodernos proporcionen recursos suficientes para una novedad que no sea una mera réplica de lo viejo y que no pueda ser recuperada por un capital que ya es demasiado tardío para ser todavía moderno. Y es muy posible que tales imaginarios nuevos - de cosas sorprendentes "por venir"- no incluyan entre ellos la historia y la ética tal y como las hemos conocido, o las excluyan del todo» ${ }^{30}$. Veamos cómo llega Jenkins a esta conclusión, una conclusión que es, a la vez, un diagnóstico y una invitación. Pero, primero, veamos con un poco de detenimiento la clase de juicio que Jenkins aplicó a la historia.

En Rethinking History, Jenkins nos brinda un examen crítico de los aspectos teóricos y prácticos de la disciplina histo- 
riográfica en busca de una respuesta a las preguntas ¿qué es la historia? y ¿por qué la historia significa tantas cosas distintas a tantas personas? Lo primero que resalta Jenkins es que la historia no se hace para sí misma, sino que siempre es hecha por y para alguien ${ }^{31}$. La historia, desde el punto de vista teórico - es decir, lo que podemos concluir pensando en lo que la historia es en teoría, no en la práctica-, está compuesta de epistemología, metodología e ideología. La epistemología nos enseña que nunca podremos conocer el pasado, ni objetiva ni totalmente, y que existe un abismo entre el pasado y la historia. La historia es un discurso sobre el pasado, pero categóricamente diferente de él ${ }^{32}$. Los análisis sobre la metodología nos avisan de que existen tantos métodos como intereses y objetivos socio-políticos, es decir, que la historia es un campo de batalla entre identidades contrapuestas y que cualquier intento metodológico de incluir alguna deja fuera, irremediablemente, a otras. En ese campo de batalla de la historia, las diferentes personas, clases y grupos de una comunidad construyen interpretaciones del pasado que son, a la postre, autobiográficas - es decir, identitarias-, y lo hacen para autocomprenderse, autoconstruirse $y$, en definitiva, autocomplacer$\mathrm{se}^{33}$. No hay historia definitiva alguna fuera de este juego de poderes y presiones. El pasado puede ser infinitamente redescrito, re-representado ${ }^{34}$. En el fondo, la historia implica a la teoría y la teoría presupone una ideología ya que responde a intereses y objetivos de diversa índole (a los de los grupos dominantes pero también - y cada vez más- a los de los grupos subordinados, silenciados, excluidos, etc.). No hay escape de este círculo vicioso. La historia, tanto desde el punto de vista de la teoría como de la práctica, se construye en los intersticios de estos intereses y presiones. Por ejem- plo, estudiando cómo funciona en la práctica, podemos afirmar que la historia es producida por un grupo de trabajadores, llamados historiadores, que cuando van a trabajar llevan con ellos valores, posiciones políticas y morales, perspectivas ideológicas, presuposiciones epistemológicas, rutinas y procedimientos - es decir, métodos - , otros materiales de estudio y distintas presiones personales, familiares, laborales, editoriales, etc. Y esto sucede tanto en la fase de investigación en archivos o en bibliotecas como en la fase en la cual el historiador se sienta a escribir - a representar- el pasado. Como ha subrayado Hans Kellner, cada profesión produce y ampara un sistema de ansiedades y de presiones que, más que cualquier otra cosa, identifica a sus miembros como filósofos, críticos, abogados, y, cómo no, historiadores ${ }^{35}$. Sande Cohen, desde una posición extrema, considera que el sistema de investigación y de producción historiográfica es, actualmente, una «colosal pieza de narcisismo» profesional, donde no se asegura ni la calidad ni el interés social de la obra, simplemente se produce para medrar en la academia conforme a las reglas previamente establecidas ${ }^{36}$. Este proceso, que no contribuye a la libertad universitaria, asegura - por el contrario- el mantenimiento de la jerarquía científica y del punto de vista académico sobre el pasado. Por tanto, en fin, todas estas razones epistemológicas, metodológicas, ideológicas y prácticas, hacen problemática la transformación del pasado en historia ${ }^{37}$.

No obstante todas estas críticas, Jenkins ofrece una definición de lo que la historia es para él: «la historia es un discurso cambiante y problemático, que aparentemente trata sobre un aspecto del mundo, el pasado; este discurso es producido por un grupo de trabajadores con mentalidad actual (abrumadoramente, en nuestra cultura, por historiadores asala- 
riados) que realizan su trabajo de manera mutuamente reconocible, que están epistemológica, metodológica, ideológica y prácticamente posicionados y cuyos productos, una vez puestos en circulación, están sujetos a una serie de usos y abusos que lógicamente son infinitos, aunque, en realidad, por regla general, se corresponden con las bases del poder que existen en un momento dado y que estructuran y distribuyen los significados de las historias a partir de un espectro que se despliega desde los dominantes a los marginados» ${ }^{38}$. En el capítulo 2, Jenkins presenta sus ya conocidos argumentos sobre diversas cuestiones tocantes a la naturaleza de la historia, cuestiones que no son sino ramificaciones agrupadas en torno a la cuestión de qué es la verdad: sobre la objetividad, sobre la relación entre los hechos y su interpretación ${ }^{39}$, sobre los prejuicios, sobre la empatía, sobre los tipos de fuentes y sobre la relación entre las fuentes y las pruebas, sobre la causalidad, sobre si la historia es un arte o una ciencia, etc. Para resumir todas estas cuestiones con una sola respuesta, diré que Jenkins mantiene una posición escéptica, aunque no cínica ni pesimista. Así, afirma que la verdad del pasado nos elude, que la historia es intersubjetiva —más que objetiva - e ideológicamente comprometida, que la supuesta objetividad e imparcialidad de la historia son sendas quimeras ${ }^{40}$, que la empatía es vista erróneamente como un defecto ${ }^{41}$, y que la historia es algo distinto a una ciencia o a un arte: es algo sui generis. Los textos historiográficos no son estrictamente cognitivos o descriptivos, sino también -y por encima de todo-, intentos especulativos, invitaciones a imaginar el pasado de múltiples maneras ${ }^{42}$.

Por tanto, para concluir, podríamos decir lo siguiente. La crítica de Jenkins al discurso historiográfico, tal y como lo conocemos, implica subrayar el hecho de que se olvida - o esconde, ideologizándose- su naturaleza contingente y cultural. Este punto viene expresado en ¿Por qué la historia? con meridiana claridad: «vivir en una cultura, afirma Jenkins, es vivir en forma significativa y a través de un código, de un lenguaje; es estar constituido literalmente dentro de imaginarios que producen lo que se entiende por realidad, de modo que esa residencia en un lenguaje es simplemente la residencia en la realidad» ${ }^{43}$. Visto así, el pasado es imaginado por los historiadores, pero no en el sentido de que no ocurrió efectivamente —ningún teórico postmoderno afirma tal cosa-, sino en el sentido de que somos nosotros quienes aportamos el significado a ese pasado, en términos, por ejemplo, de las significaciones y los propósitos que ese pasado se supone que tiene para nosotros. Somos nosotros, escribe Jenkins, quienes dictamos la historia: ésta es imposible sin la clase de abrazo textual a que es sometida por parte de los historiadores. Nosotros somos la fuente de ese pasado significativo, de ese pasado que es compartimentado, seleccionado, investigado y escrito por multitud de investigadores y de escritores. Es evidente que la historia contiene un componente cognoscitivo, epistemológicamente manejable, en el nivel de la afirmación singular - lo que Jenkins llama los «arreglos sintácticos del pasado» ${ }^{44}$ _, en la medida en que no seamos idealistas radicales, pero lo que denuncian los postmodernistas como Jenkins es la dificultad de establecer los métodos y las formas de acrecentar nuestro conocimiento sobre el pasado más allá del nivel de la sintaxis, es decir, en el nivel semántico, en el nivel narrativo, que es donde se mueven las intenciones representativas de la historiografía, en lo que Ankersmit denomina las «sustancias narrativas» ${ }^{45}$, intenciones que no implican una sustitución de las teorías de la correspondencia, sino la 
aceptación de la naturaleza estética de la historiografía ${ }^{46}$. Es este paso - de la frase al texto, de la afirmación al discursoel que ninguna teoría, empirista o no, ha conseguido exponer y explicar convincentemente, como han resaltado tanto defensores de la postmodernidad como Rorty, como críticos de ella, como George Steiner.

La conclusión de todo lo dicho hasta aquí está expuesta con claridad en la introducción de ¿Por qué la historia?: «el pasado, tal y como se constituye mediante sus huellas aún existentes, siempre es aprehendido y apropiado en forma textual mediante capas sedimentadas del trabajo interpretativo anterior, así como mediante los hábitos de lectura y las categorías/conceptos de nuestras prácticas metodológicas anteriores/presentes» ${ }^{47}$. Como diría Ankersmit, la historiografía - la clase de discurso textual que producen los historiadores - no es más que el conjunto de representaciones sustitutivas 48 que ponemos en lugar del pasado ausente para narrarlo e interpretarlo. «No hay representaciones: no hay pasado», sentencia Ankersmit 49 . Finalmente, lo que queda es que «la historia con mayúsculas se halla en escombros y la historia con minúsculas es incapaz de alcanzar un mayor desarrollo» ${ }^{50}$. Posteriormente, Jenkins afirmará que su creencia y su argumento es «que no hay reglas no problemáticas o normas de traducción o de transcripción (tal y como se articulan a través de múltiples métodos, técnicas y prácticas) que permitan al pasado (todo lo que ha sucedido "antes de ahora") ser la verdad total o ser objetiva o imparcial o científicamente representado como "conocimiento histórico" en el nivel del texto histórico, y que esta condición, más que ser deplorable, es, una vez más, lo mejor que podemos esperar» ${ }^{51}$.

Finalmente, en esta primera etapa de la obra de Jenkins, nuestro autor ter- mina por proponer una defensa del tipo de historia reflexiva, postmoderna, que denuncia los usos ideológicos de la - supuesta - objetividad e imparcialidad de las viejas historias con «mayúscula»y con «minúscula» ${ }^{52}$. Ésta es la posición que ha mantenido en sus tres primeros libros, desde Rethinking History hasta The Postmodern History Reader, pasando por On "What is History?» ${ }^{53}$. Conviene recordar que la intención principal de esta primera época en el pensamiento jenkinsiano fue desarrollar una reflexión auto-consciente sobre la naturaleza de la historiografía. Pero en el último capítulo del libro Rethinking History -Doing History in the Post-Modern World-, Jenkins presentó una declaración de intenciones acerca de la posibilidad de una historia postmoderna, más acorde con su espíritu crítico y emancipador. Sin embargo, en un punto entre estos años y la preparación y redacción de ¿Por qué la historia?, Jenkins comenzó a considerar la posibilidad de deshacerse de cualquier tipo de historias, incluidas las propuestas historiográficas postmodernas ${ }^{54}$. Ésta es la materia que veremos en el siguiente apartado.

\section{Relativismo: reimaginar la historia criticando sus intereses, funciones y usos}

Jenkins nos recuerda que en la actualidad son pocas las personas que defienden la historia metanarrativa - la historia con «mayúsculas» o historia upper case-, que ha demostrado ser tan increíble e ideológica que merece ser olvidada. Sin embargo, todavía podemos encontrar multitud de personas que defienden $-\mathrm{y}$, por lo tanto, practican o leen- el tipo de historia con «minúsculas» - $\mathrm{O}$ historia lower case-, profesional y académica, que los historiadores escriben. Además de los propios historiadores postmodernos, entre los cuales quiero citar a Hans 
Kellner ${ }^{55}$, Allan Megill 56, Robert A. Rosenstone $^{57}$, H. U. Gumbrecht ${ }^{58}$, Simon Schama ${ }^{59}$, etc. Sin embargo, en este punto, el postmodernismo, según Keith Jenkins, «señala el fin de la historia tal y como la conocemos, no sólo en su metanarrativa modernista y en sus formas académicas, profesionales, sino de la historia per se» ${ }^{60}$. Después de analizar la obra de Hayden White, de Frank Ankersmit y de otros autores postmodernos, Jenkins llega a la conclusión de que, al igual que la historia con «mayúscula» - las metanarrativas_-, la historia con «minúscula» es, en la actualidad, un discurso moribundo, está comenzando a desaparecer de las conversaciones, y debe ser contemplado con mucha incredulidad por su naturaleza epistemológica débil y por su carácter fuertemente ideológico. De hecho, afirma Jenkins, deberíamos abandonar y cambiar este tipo de discursos historiográficos por nuevos imaginarios —en el sentido en que concibe el término Castoriadis-: nuevos imaginarios morales postmodernos, «más allá del fin de las historias» ${ }^{61}$, algo que es, si no revolucionario, por lo menos sí utópico ${ }^{62}$.

Una vez analizada y estudiada la naturaleza constructiva, textual y ficcional de las obras historiográficas -estudiado en el apartado anterior- - el argumento de Jenkins para reprender a las micronarrativas y para imaginar y proponer un mundo futuro sin historia, es el siguiente: por un lado, critica la ideología inherente en dicha disciplina al hacer pasar por natural o científica una práctica que es manifiestamente cultural. «La historia, escribe Jenkins, no es en absoluto un fenómeno natural ni tiene nada de eterno», algo con lo que muchos historiadores están de acuerdo ${ }^{63}$. La historia - es decir, la forma en que percibimos y escribimos sobre el tiempo en nuestras sociedades y culturas - es un discurso contingente, no absoluto. «"Es obvio" que nunca hemos visto nada parecido a los géneros históricos occidentales con mayúscula y con minúscula de los siglos XIX y XX, en ningún otro tiempo y lugar. Porque nunca jamás ha habido, en ninguna otra parte de la Tierra, en ningún otro tiempo, un modo de historizar el pasado en esa forma» ${ }^{64}$. En definitiva, todas las culturas tienen un pasado pero no todas tienen «historia» ${ }^{65}$. Aquí, las críticas que minaron los fundamentos metafísicos, ontológicos y epistemológicos de la historia con «mayúsculas» pueden ser aplicadas con la misma efectividad a la historia con «minúsculas».

A este conjunto de cuestiones Jenkins pone la etiqueta de antifundamentalismo, es decir, de una clase de escepticismo sobre la naturaleza, metodología y funciones de un tipo de discurso que, como todos los demás, es accidental; pero, por otro lado, Jenkins resalta también que, si existen diferentes formas de apropiarse del pasado - fundamentalmente porque existen diversos intereses y diversas condiciones que influyen en la investigación y en la escritura de la historia-, no nos queda sino reconocer que la historia «propiamente dicha», la historia defendida por los historiadores, no es más que algo relativo a dichas condiciones y a dichos intereses ${ }^{66}$. Tenemos, por tanto, un pasado pero muchas historias. Como escribe Jenkins, «el relativismo sugiere que el pasado puede ser apropiado de modo legítimo en una multiplicidad de formas y para una multiplicidad de propósitos» ${ }^{67}$. Y es que todo el mundo tiene derecho a estudiar el pasado y a darle el uso que considere apropiado, ya que el pasado no es propiedad de nadie y tampoco hay que dar crédito a los llamados «guardianes del pasado», quienes se autolegitiman para decirnos qué ocurrió realmente en el pasado y para qué podemos usar ese conocimiento ${ }^{68}$.

Entonces, la pregunta es: ¿cómo discriminar entre la multiplicidad de relatos 
cuando el criterio ya no es la verdad, especialmente privilegiada por la academia, sus métodos y sus relaciones de autoridad y de poder? Y ¿cómo multiplicar los usos del pasado sin caer en la trivialidad? Las respuestas a estas cuestiones son difíciles de encontrar en la obra de Jenkins, quien, en estos asuntos, abandona la crítica sistemática y se inclina por un impresionismo seductivo ${ }^{69}$.

En la tercera parte de su ¿Por qué la historia? — la parte más importante para nuestro argumento-, Jenkins se apoya en dos autores como Elizabeth Deeds Ermarth y David Harlan para desplegar sendas propuestas. La primera de ellas es que debemos olvidarnos de la historia - no solamente de las metanarrativas (tan criticadas y denostadas en la actualidad), sino también de las micronarrativas (es decir, del tipo de historia que producen los historiadores)—, y que debemos sustituirla por nuevas organizaciones del tiempo, en la forma ensayada por el libro Sequel to History, de Ermarth. La segunda de las propuestas de Jenkins es que, siguiendo a Harlan, debemos olvidarnos de la ética pero sin renunciar a la moralidad - o lo que es lo mismo, que debemos sustituir la ética existente por nuevas moralidades de «elección no fundamentada», reconociendo «la locura de las decisiones morales indecidibles», en el sentido derridiano- ${ }^{70}$. Es decir, hay que reconocer y admitir la aporía: una reflexión moral emancipatoria no puede evitar reflexionar sobre ella pero sí puede ser fructífera sin la «historia». La tesis de Jenkins es que «para avanzar hacia el futuro en formas radicales y emancipatorias todo lo que necesitamos son imaginarios postmodernos sans histoire» ${ }^{71}$, en la línea abierta por las teorías y las críticas de autores de tipo postmoderno como Barthes, Foucault, Deleuze ${ }^{72}$, Derrida, Lyotard, Baudrillard ${ }^{73}$, Irigaray, Kristeva, Spivak, Butler, Laclau, Mouffe, Rorty,
Vattimo, White, Ankersmit, Ermarth o Harlan, ninguno de los cuales es un historiador profesional ${ }^{74}$. Si cada uno de estos autores puede proporcionar lo necesario para construir análisis, retóricas y propuestas emancipatorias, quizás cualquiera de nosotros también pueda hacerlo ${ }^{75}$. Ni siquiera necesitamos desarrollar propuestas historiográficas postmodernas, ni preocuparnos por su posible idoneidad: todo lo que necesitamos para desarrollar propuestas políticas emancipatorias y de justicia social proviene de la reflexión ético-política, no del estudio del pasado ni, por tanto, de la historia ${ }^{76}$. La pregunta más atractiva e, incluso, la más urgente — para Jenkins - es, entonces, sobre la viabilidad de cualquier tipo de historia: ¿por qué seguir preocupándose por historiar el pasado?

Lo que Jenkins propone no es el fin del desarrollo histórico - algo cercano a lo que propuso en su día el libro de Fukuyama, El fin de la historia y el último hombre-, o el fin de la vida como tal, o que el pasado no vaya a seguir siendo evocado de diversas maneras. No, nada de esto es planteado por Jenkins. Lo que está afirmando es, ni más ni menos, que la modernidad esculpió unas formas significativas y útiles de aprehender el pasado, que están siendo liquidadas $-\mathrm{y}$, en un sentido agónico, casi arrastradaspor el propio fin de la modernidad. O, como diría Deeds Ermarth, «ahora la historia adopta la interesante posición de confrontar su propia historicidad» $\mathrm{y}$ —añade Jenkins - su propia finitud ${ }^{77}$. Cuando miramos por encima de nuestros hombros al Medievo, por ejemplo, aceptamos que, con la desaparición de tal período histórico, se desvanecieron también las visiones medievales del pasado, sus concepciones sobre el tiempo, sobre la relación entre el pasado, el presente y el futuro. Entonces, «¿por qué no aceptar con la misma facilidad que las historias 
construidas en y para la modernidad llegarán a su fin cuando ésta termine?» ${ }^{78}$. La constatación de esta interpretación no debe ser causa de desasosiego o de pesimismo alguno. Al contrario. Debemos abrazar un postmodernismo no historizante, olvidando las formas y las configuraciones historiográficas modernas, y debemos imbuirnos en el abismo del flujo interminable y relativista de la interpretación ${ }^{79}$, «con el fin de contribuir, de una forma emancipadora y democrática, al cambio, tanto dentro como más allá del capitalismo» porque, evidentemente, el capitalismo no puede ser el «fin de la historia» ${ }^{80}$.

O dicho de otra manera: una vez que comprendemos la naturaleza contingente, relativa e ideológica y, por tanto, políticamente comprometida de cualquiera de nuestros intentos por aprehender el pasado ${ }^{81}$, la pregunta es: ¿Qué queremos ahora de él? ¿En qué nos puede ayudar? ¿Para qué nos puede servir? Y ¿para qué nos puede servir políticamente? Si la historia ya no es nuestra maestra de vida, nuestro particular tribunal de apelaciones, nuestro particular aviso para navegantes, ¿qué puede ser ahora? ¿Y cómo deberíamos usarla? ${ }^{82}$ La respuesta de Jenkins es que la historia no nos proporciona ningún objetivo político universal, en la misma medida en que su potencial cognoscitivo está también sometido a las presiones de la ideología y de la cultura ${ }^{83}$. Sin embargo, Jenkins sustituye todas estas cuestiones por una opción que considera de vital importancia: «¿por qué no olvidarnos de la historia y vivir en imaginarios sin ella?» ${ }^{84}$, tanto en los niveles social y político, como en el educativo. Hayden White apuntó, a este respecto, que la enseñanza de la historia no debería «liberar» a ningún alumno —al menos teniendo en cuenta que lo importante no es independizarlo de algo sino para algo — sino, más bien, mejorar sus facultades para pensar críticamente sobre los clichés que ha ido recibiendo de la sociedad y del sistema educativo. Y es que White considera que dicha sociedad prefiere un alumno pasivo, incluso apático, respecto del ejercicio de los derechos humanos, por ejemplo, lo que disminuye a su vez la capacidad de denunciar y luchar contra sus constantes violaciones ${ }^{85}$. Siguiendo a White, Jenkins estaría más cerca de la posición de la historiografía marxista británica, para la cual se debería educar «a aquellos para quienes la lucha es hoy una necesidad concreta con las experiencias históricas de aquellos otros para quienes la lucha fue una necesidad concreta ayer» ${ }^{86}$. Pero la historia no debería cumplir un papel primordial en esta tarea. Y es que, desde Marx, sabemos que existen alternativas — teóricamente más sofisticadas - a la historiografía para explicar y comprender la realidad social, tanto la presente como la pasada, como la sociología o la filosofía críticas. La historia, qué duda cabe, favorece a la educación - es decir, a la formación de una identidad - más que al conocimiento ${ }^{87}$.

Los autores con los que Jenkins dialoga en este momento de su exposición son, como ya hemos dicho, Elizabeth Deeds Ermarth y David Harlan ${ }^{88}$. Esta forma dialógica de reflexión, típicamente jenkinsiana, busca aprovechar las propuestas de los demás en el rodeo que supone apuntalar el argumento propio ${ }^{89}$. De la primera acoge la propuesta de otras organizaciones del tiempo distintas a la lineal, típicamente occidental $-\mathrm{O}$, mejor dicho, típicamente moderna 90 - y, en su lugar, propone nuevas formas (como cronopios, tiempos rítmicos y anacronismos ${ }^{91}$ ), mientras que del segundo recoge la sugerencia de estudiar los textos históricos, no en sus contextos, sino en nuestro contexto, directamente, permitiendo una combinatoria moral donde el juego de textos y contextos - es decir, donde 
descontextualizar textos - nos permita armar imaginarios eclécticos y antifundacionalistas que refuercen la moralidad relativista que defiende Jenkins ${ }^{92}$.

El tiempo rítmico de Deeds Ermarth modifica o abandona radical y totalmente la dialéctica, la teleología, la trascendencia y la supuesta neutralidad del tiempo histórico, a la vez que sustituye el viejo cogito cartesiano por una diferente subjetividad - una conciencia multinivelcuyo modelo es extraído de las novelas y los cuentos de Julio Cortázar, Robbe-Grillet y Nabokov ${ }^{93}$. Como escribe Jenkins, ahora es posible vivir en nuevas organizaciones del tiempo, organizaciones rítmicas, las cuales, a la vez que indican el fin de las nociones modernistas sobre el tiempo, muestran que podemos vivir fuera de la historia. El tiempo postmoderno es el tiempo de los cronopios, de la performatividad, de la improvisación, del jazz, del bricolaje, incluso del cine y de la cultura visual ${ }^{94}$, etc. «I swing, therefore I am» ${ }^{95}$, termina por concluir.

Las obras que quebrantan la historia tradicional también proporcionan nuevas preguntas y nuevas oportunidades prácticas - nuevos experimentos 96 - que desbaratan la seguridad anterior, pero esta inseguridad debe ser tomada con alegría ${ }^{97}$. Como afirma Jenkins, «la postmodernidad ofrece nuevos nacimientos» ${ }^{98}$. En el fondo, una vez que comenzamos a ver el tiempo como algo no neutral ni absoluto, nuestras maniobras mentales inventadas y construidas, postmodernas, nos permiten darnos cuenta de que hemos dejado atrás el tiempo de la profesión, del corporativismo y de la retórica del poder para adentrarnos en el juego de la libertad $y$, por tanto, de la responsabilidad: de fomentar un punto de vista flexible ${ }^{99}$. Sin embargo, Ermarth no desea aplicar este esquema del tiempo rítmico al pasado, «no es que desee, por ejemplo, reinterpretar el Medievo tardío o decir algo nuevo acerca de la condición de las mujeres de la clase trabajadora en el siglo XIX: más bien quiere olvidar el pasado histórico en favor de aventuras orientadas hacia el [presente y el] futuro» ${ }^{100}$, sin ansiedad ninguna, con júbilo, con esperanza y con intenciones emancipadoras. En este sentido, es una propuesta similar a la presentada por Hayden White mediante su concepto de "progressive history», que el propio White compara con la «historia crítica» de Nietzsche, una historia fundamentalmente comprometida con el futuro, más que con el pasado: con un futuro que nos gustaría heredar más que con algún otro que estemos obligados a soportar ${ }^{101}$. O, mejor dicho, Jenkins propone decir adiós a la «historia» para centrarnos en imaginar y construir un futuro sin el tipo de cargas que produce el pasado histórico historizado ${ }^{102}$.

Para Harlan, la historia era - hasta mediados del siglo Xx y, por lo menos, en los EE.UU.- - una especie de «conversación transgeneracional» (transgenerational conversation), mientras que, a partir de los años sesenta y setenta, tanto las prácticas desideologizadoras de parte de la izquierda - que desenmascaraban los intentos de la historiografía anterior de racionalizar la esclavitud, de excusar el racismo o de apoyar el imperialismo, por ejemplo - como las críticas de la teoría postmoderna - que desmontaban la supuesta objetividad de la historiografía profesional-, compelieron a la historia a dar un vuelco radical hacia el escepticismo y el relativismo postmetafísico y postmoderno ${ }^{103}$. Como escribe Harlan, «la postmodernidad es, en esencia, una extensión y una elaboración de la vieja idea según la cual no tenemos forma alguna de ver, pensar o desear que no hayamos adquirido de la cultura circundante» ${ }^{104}$. Jenkins asegura que el postmodernismo no es una moda, ni una corriente de crítica del discurso historiográfico 
que pueda ser incorporado en el mainstream cultural una vez que sus «excesos» sean pulidos. No. El postmodernismo consiste, precisamente, en esos excesos, e implica alcanzar una actitud militante y radical «que no sólo socava el contenido sino las formas ficcionales y gramaticales de las historias modernas, sin una pizca de disculpa o de nostalgia» para ofrecer, en su lugar, nuevas gramáticas orientadas al futuro más que al pasado $\mathrm{y}$, como consecuencia, nuevas estrategias de crítica y emancipación políticas ${ }^{105}$.

Mientras que Deeds Ermarth considera que el lenguaje narrativo postmoderno ha socavado el tiempo histórico y lo ha sustituido por una nueva construcción de la temporalidad - a la que llama «tiempo rítmico», rhythmic time ${ }^{106}$ Harlan afirma que el único objetivo del estudio del pasado es «lo que pueda significar actualmente para nosotros» - $-\mathrm{y}$, en este punto, Harlan no está solo, puesto que le acompañan Ankersmit y White-. Como sugiere Jenkins, lo que propone Harlan implicaría una especie de «estudios de apropiación» o de «estudios temporales», no de estudios históricos per se ${ }^{107}$, algo que, quizás, ha mencionado Martin L. Davis al proponer, irónicamente, la creación de unos auto-reflexivos departamentos universitarios - llamados Historics ${ }^{108}$ _, que hagan explícitas, por ejemplo, las paradójicas conexiones de la academia con el capitalismo. Por su lado, Cohen propone desburocratizar las universidades y los planes de estudio ${ }^{109}$. Sin embargo, las propuestas de Jenkins no son ni tan explícitas ni tan específicas en esta materia.

\section{Conclusiones inconclusas}

Como hemos visto, la tesis fundamental de Jenkins sería que «el-pasado-como-historia», the-past-as-history ${ }^{110}$, no existe fuera de las apropiaciones textuales que los historiadores construyen. Así, el pasa- do sólo nos llega a través de dispositivos de ficción —es decir, imaginados-que seleccionan, jerarquizan y dotan de significado al pasado, al servicio de intereses y poderes del presente, contemporáneos del historiador. Es lo que George Steiner ha llamado «imágenes del pasado» ${ }^{111}$. «El pasado como historia siempre ha estado y siempre estará necesariamente configurado, envuelto en tropos, figurado en tramas, leído, mitificado e ideologizado en formas que nos resulten convenientes» ${ }^{112}$. El pasado siempre está sobre determinado, en última instancia, por lo estético, por el fenómeno estético, representativo, que ensambla mecanismos retóricos y figuras de estilo en una narración interpretativa que implica, invariablemente, una toma de posición ideológica, es decir, política ${ }^{113}$. En este sentido, la historia ha sido siempre - y siempre será- un producto estético, como no se han cansado de subrayar Hayden White, Ankersmit, Jenkins y otros pensadores tan poco sospechosos de ser postmodernos como Danto o Gombrich ${ }^{114}$.

Pero esto es simplemente el comienzo de la obra de Jenkins. Por su parte, los desenlaces argumentales de Jenkins son radicales en la forma y polémicos en el contenido; son a la vez lacónicos y desarrollados, son a la vez comienzos y finales, críticas y esperanzas. El principal de todos ellos es que no necesitamos ninguna historia para ubicarnos en el presente pero tampoco para imaginar posibles futuros; no lo necesitamos para comprender los tiempos presentes ni para construir proyectos políticos emancipadores, reflexivos pero antifundacionalistas ${ }^{115}$. El ejemplo de esto es que una parte muy importante de la labor intelectual de los postistas es realizada sin conciencia histórica ninguna y sin que ninguno de ellos sea un historiador. Es verdad que muy esporádicamente — sobre todo en la actualidad - han sido los historiadores los que han propuesto mapas po- 
líticos emancipadores para sus comunidades ${ }^{116}$ pero, sin embargo, la crítica de Jenkins no deja de ser más certera por este hecho. Rorty es, en este sentido, un autorizado paradigma: «el estudio del pasado por sí mismo, en sí mismo y para sí mismo no tiene interés alguno para Rorty, y no hay razón para que lo tenga para nosotros»» ${ }^{117}$. Socorridos por la deconstrucción derridiana ${ }^{118}$, por el différend de Lyotard ${ }^{119}$, por el antifundacionalismo de Rorty, por los simulacros y la indiferencia de Baudrillard, por el textualismo y la sublimidad de White, por la historicidad post-kantiana de Ankersmit, por los cronopios de Ermarth y por el relativismo de Harlan, estamos ahora en disposición de decirle adiós a la historia y de abrazar otra moralidad y otra historicidad. Merece la pena citar en extenso un párrafo de la introducción de Jenkins a su ¿Por qué la historia?: «el escepticismo y el relativismo parecen ser entonces simplemente cosas que podemos aceptar y con las que podemos convivir con alegría, conscientes de nosotros mismos, tal como lo hacían los sofistas antiguos [y nos ha recordado recientemente, entre otros, Stanley Fish ${ }^{120}$ ] y lo hacen los sofistas retóricos postmodernos: no parece haber ninguna alternativa fundacional: eso es lo que hemos comprendido gracias a la "conciencia de uno mismo". Por consiguiente, es por este tipo de razones que creo que ahora empezamos realmente a vivir fuera de la historia y de la ética y dentro del tiempo y la moralidad en formas más relajadas y, espero, también emancipatorias» ${ }^{121}$.

Ahora podemos imaginar un sistema político emancipador sin recurrir obsesivamente a la experiencia del pasado. En definitiva, Jenkins se declara - como Hayden White-, un relativista moral y un escéptico reflexivo, ya que considera que ambas posturas son la base del reconocimiento de las diferencias y de la diversidad $\mathrm{y}$, en última instancia, de la coopera- ción entre ellas ${ }^{122}$. Por otro lado, cuando ésta última falla, el relativismo garantiza la tolerancia mejor que cualquier forma de universalismo totalizador, como ya habían afirmado Rorty y Lyotard ${ }^{123}$. En este sentido, Jenkins está de acuerdo con Alain Badiou, quien considera el ser mismo de la humanidad no desde un universalismo esencialista, sino como la misma multiplicidad, como la misma diferencia, y ello sin renunciar a la idea de la emancipación humana ${ }^{124}$. Frente al universalismo Jenkins plantea, por tanto, un relativismo que insiste especialmente en el relativo valor cognoscitivo de la historia - la historia es interpretación, es decir, el conjunto de representaciones «fallidas», abiertas ${ }^{125}$-, en la riqueza del juego entre esas interpretaciones, en historizar la misma labor historiográfica $y$, en definitiva, en transformar en acción crítica y emancipadora el escepticismo epistemológico. Así, ahora podemos desarrollar un proyecto político postmoderno - como el que sugiere Michael Walzer - conscientes de la violencia involucrada en la difusión de una identidad - esencial — común, que estandariza las conductas, y asentados en la convicción del valor de la diferencia ${ }^{126}$. Por último, una pregunta surge de inmediato. Si Appleby, Hunt y Jacob tienen razón, y el escepticismo y el relativismo actuales provienen de la insistente democratización de la sociedad ${ }^{127}$, ¿defender la objetividad y el esencialismo implica una defensa de la jerarquía y del statu quo y, a la postre, una crítica del poder emancipador de la democracia? El mismo Derrida planteaba que la democratización de una sociedad se mide por la posibilidad que tienen las personas y los grupos de participar y acceder «al archivo, a su constitución y a su interpretación» ${ }^{128}$ : es decir, a construir su propia historia.

Con las implicaciones políticas de esta cuestión centelleando de fondo, dejamos aquí la exposición e invitamos al 
lector a que siga la obra del profesor Jenkins en busca de tentativas optimistas 129 y respuestas provisionales a esta empresa de refiguración de una democracia relativista y emancipadora y de lucha por un mundo menos violento y cruel de lo que ha sido hasta ahora ${ }^{130}$.

\section{BIBLIOGRAFÍA}

Ankersmit, F. R. (2009): «Danto's Philosophy of History in Retrospective», Journal of the Philosophy of History, 3, 2, pp. 109-145.

AnKersmit, F. R. (2006): "“Presence" and Myth», History and Theory, 45, 3, October, pp. 328-336.

Ankersmit, F. R. (2005): Sublime Historical Experience, Stanford University Press, Stanford.

AnKersmit, F. R. (2003): «Invitation to Historians», Rethinking History, 7, 3, pp. 413-437.

AnKersmit, F. R. (2001): Historical Representation, Stanford University Press, Stanford.

AnKersmit, F. R. (1983): Narrative Logic. A Semantic Analysis of the Historian's Language, Martinus Nijhoff, La Haya.

ANKersmit, F. R.; Domanska, E. y Kellner, H. (2009): Re-Figuring Hayden White, Stanford University Press, Stanford.

Appleby, J.; Hunt, L. y JaCoB, M. (1998): La verdad sobre la historia, Andrés Bello, Santiago de Chile.

Attridge, D. (1987): Post-Structuralism and the Question of History, Cambridge University Press, Cambridge.

BADIOU, A. (2006): «La potencia de lo abierto: Universalismo, diferencia e igualdad», Archipiélago, 73-74, diciembre, pp. 21-34.

BAGHRAMIAN, M. (2005): Relativism, Routledge, Abingdon y New York.
Bertens, H. y Natoli, J. (2002): Postmodernism: The Key Figures, Blackwell, Oxford.

Bolaños de Miguel, A. M. (2009): «Keith Jenkins sobre la historia, la política y el pasado», en JenKINS, K., Repensar la Historia, Siglo XXI, Madrid, pp. 91-105.

Bolaños de Miguel, A. M., «Figuras del pasado: obsesión, cadenas y horizontes», Historia y Política, 17, 2007, pp. 255-263.

BREISACH, E. (2003): On the Future of History: The Postmodernist Challenge and Its Aftermath, University of Chicago Press, Chicago.

Clark, E. A. (2004): History, Theory, Text. Historians and the Linguistic Turn, Harvard University Press, Cambridge.

CoHen, S. (2006): History Out of Joint. Essays on the Use and Abuse of History, The Johns Hopkins University Press, Baltimore.

Cohen, S. (1999): Passive Nihilism: Cultural Historiography and the Rhetorics of Scholarship, St. Martin's Press, New York.

CoHen, S. (1996): «Reading the Historians' Resistance to Reading: An Essay on Historiographic Schizofrenia», CLIO, 26, 1, pp. 1-28.

Cohen, S. (1993): Academia and the Luster of Capital, University of Minnesota Press, Minneapolis.

Connor, S. (1996): Cultura Postmoderna. Introducción a las teorías de la contemporaneidad, Akal, Madrid.

DAvies, M. L. (2006): Historics, Why History Dominates Contemporary Society?, Routledge, Abingdon y New York.

DAVIES, M. L. (1989): «History as narcissism», Journal of European Studies, 19, 4, pp. 265-291. 
Deeds Ermarth, E. (2004): «Ethics and Method», History and Theory, 43, 4, December, pp. 61-83.

DeEDS ERMARTH, E. (1998): Realism and Consensus in the English Novel, Edinburgh University Press, Edinburgh.

Deeds ERmarth, E. (1992): Sequel to History. Postmodernism and the Crisis of Representational Time, Princeton University Press, Princeton.

DERridA, J. (1996): Archive Fever: a Freudian impression, The University of Chicago Press, Chicago.

Domanska, E. (2009): «Frank Ankersmit: From narrative to experience», Rethinking History, 13, 2 June, pp. 175-195.

DomAnsKA, E. (2008): «A conversation with Hayden White», Rethinking History, 12, 1, march, pp. 3-21.

FIsH, S. (1989): Doing What Comes Naturally. Change, Rhetoric and the Practice of Theory in Literary and Legal Studies, Clarendon Press, Oxford.

Godoy, C. (1999): «Keith Jenkins (ed.), The Postmodern History Reader», Estudios Sociales, Universidad $\mathrm{Na}$ cional del Litoral, Santa, 17, 1999, pp. 197-202.

GonzÁlez de Oleaga, M. (2003): «Elogio de la vehemencia: A propósito de la obra de Keith Jenkins», Historia y Política, 10, pp. 340-348.

GonzÁlez de Oleaga, M. y Bolaños de Miguel, A. M. (2008a): «Vértigos y prácticas historiográficas postmodernas», en Rodríguez GonZÁlez, C. y VAldÉs MiYARES, R. (eds.), Historia y Representación en la cultura global, KRK, Oviedo, pp. 40-50.

GonzÁlez de Oleaga, M. y Bolaños de Miguel, A. M. (2008b): «Teoría y práctica en la historiografía postmoderna», Revista de Libros, 136, abril 2008, pp. 15-16.
Gumbrecht, H. U. (2006): Elogio de la belleza atlética, Katz, Buenos Aires, 2006.

Gumbrecht, H. U. (2005): Producción de Presencia. Lo que el significado no puede transmitir, Iberoamericana, México.

Gumbrecht, H. U. (2004): En 1926. Viviendo al borde del tiempo, Universidad Iberoamericana, México.

HALlWARD, P. (2006): Out of this World. Deleuze and the Philosophy of Creation, Verso, London y New York.

Harlan, D. (1997): The Degradation of American History, University of Chicago Press, Chicago.

HASKell, T. L. (1998): Objectivity is not Neutrality. Explanatory Schemes in History, Baltimore y London, The Johns Hopkins University Press.

Huehls, M. (2009): Qualified Hope. A Postmodern Politics of Time, The Ohio State University Press, Columbus.

JAY, M. (1993): «The Textual Approach to Intellectual History», en JAY, M., Force Fields: between Intellectual History and Cultural Critique, Routledge, New York y London.

JENKIns, K. (2009a): At the Limits of History. Essays on Theory and Practice, Routledge, London.

Jenkins, K. (2009b): Repensar la Historia, Siglo XXI, Madrid.

JENKINS, K. (2008a): "“Nobody Does it Better": radical history and Hayden White», Rethinking History, 12, 1, March, pp. 59-74.

JENKINS, K. (2008b): «Cohen contra Ankersmit», Rethinking History, 12, 4 December, pp. 537-555.

JENKINS, K. (2008c): «Editorial: On Sande Cohen», Rethinking History, 12, 4 December, pp. 433-436.

JENKINS, K. (2007a): «The End of the Affair: On the Irretrievable Break- 
down of History and Ethics», Rethinking History, 11, 2, June, pp. 275-285. JENKINS, K. (2007b): «On the Necessary Conditions of Possibility for a Radical History», Conferencia pronunciada en la Universidad de Oviedo, el jueves 27 de septiembre de 2007.

Jenkins, K. (2006a): ¿Por qué la historia? Etica y Postmodernidad, FCE, México.

JENKINS, K. (2006b): «Postmodernism, the End of History, and Frank Ankersmit», en MACFIE, A. L. (ed.), The Philosophy of History, Palgrave, London, pp. 138-154.

Jenkins, K. (2005): «Once Upon a Time: On History». Inaugural Lecture, University of Chichester, Chichester.

JENKINS, K. (2004a): «Ethical Responsibility and the Historian: On the Possible End of a History "of a Certain Kind"», History and Theory, 43, 4, December, pp. 43-60.

JenKIns, K. (2004b): «Modernist Disavowals and Postmodern Reminders of the Condition of History Today: On Jean François Lyotard», Rethinking History, 8, 3, September, pp. 365-385.

JENKINS, K. (2004c): «On History, Historians and Silence», History Compass, $2,1$.

JENKINS，K. (2004d): «Una respuesta postmoderna a Pérez Zagorin», Historia Social, 50, pp. 119-139.

JENKINS, K. (2003a): Refiguring History. New Thoughts on and Old Discipline, London y New York, Routledge.

JENKINS, K. (2003b): Rethinking History, London y New York, Routledge.

JENKINS, K. (2003c): «On Disobedient Histories», Rethinking History, 7, 3, November, 367-389.

JENKIns, K. (2003d): «Against the Historical "Middle Ground": A Reply to Michael Coleman», American Studies in Scandinavia, 35, 1, Spring, pp. 1-22.
JENKINS, K. (2002): "The end of history», The Philosophers' Magazine, 20, autumn, pp. 46-48.

JENKINS, K. (2000a): «An English Myth? Rethinking the Contemporary Value of E. H. Carr's What is History?», en Cox, M. (ed.), E. H. Carr. A Critical Appraisal, Palgrave, New York, pp. 304-321.

JENKINS, K. (2000b): «Why Bother with History?», en Spargo, T. (ed.), Reading the Past. Literature and History, Palgrave, Basingstoke, pp. 147-155.

JENKINS, K. (1999): «Jean Baudrillard: Radical Morality and Thoughts on the End of History», Literature \& History, 8, 1, Spring, pp. 56-68.

JENKINS, K. (1998): «A Conversation with Hayden White», Literature \& History, 7, 1, Spring, pp. 68-82, pp. 72 y 74 .

Jenkins, K. (1997a): The Postmodern History Reader, Routledge, London y New York.

JenkINS, K. (1997b): "Living in Time But Outside History, Living in Morality But Outside Ethics: Postmodernism and Elizabeth Deeds Ermarth», en Sumic-Riha, J. y Luthar, O. (eds.), Power and Resistance, 2, 1997, pp. 213-232.

Jenkins, K. (1996a): "“Life is Short” A Reply to Marnie Hughes», Teaching History, 82, January, pp. 31-32.

Jenkins, K. (1996b): «No Going Back: A Case for Postmodern History», Teaching History, 84, June, pp. 34-38.

JENKINS, K. (1996c): «Teaching History Theory: a Radical Introduction», en Booth, A. y Hyland, P. (eds.), History in higher education: new directions in teaching and learning, Blackwell, Oxford y Cambridge, pp. 75-93.

Jenkins, K. (1995): On "What is History? " From Carr and Elton to Rorty and White, Routledge, London y New York. 
Jenkins, K. (1994): «Beyond the Old Dichotomies: Some Reflections on Hayden White», Teaching History, 74, January, pp. 10-16.

Jenkins, K. (1992): «The Discursive Turn: Tony Bennet and the Textuality of History», Teaching History, 66, January, pp. 7-17.

JENKIns, K. (1991): «Always Historicise: Unintended Opportunities in Nacional Curriculum History», Teaching History, 62, January, pp. 8-14.

JENKINS, K. (1986): "A-Level History. From "Skillology" to "Methodology"», Teaching History, 46, October, pp. 3-7.

JEnKINS, K. (1985): «Teaching Teachers: A Secondary History PGCE Course», Teaching History, 42, June, pp. 9-12.

Jenkins, K. (1982): "The Dogma of Nietzsche's Zarathustra», Journal of Philosophy of Education, 16, 2, pp. 251-254.

JENKInS, K. (1975): Ideology and Science in the Political Thought of F. W. Nietzsche, S. Freud and G. Sorel, 1975, copia privada.

JENKINS, K. y BRICKLEY, P. (1990): «Designer Histories: A Reply to Christopher Portal», Teaching History, 60, July, pp. 27-29.

JENKINS, K. y BRICKLEY, P. (1989): «Reflections On the Empathy Debate», Teaching History, 55, April, pp. 18-23.

Jenkins, K. y Brickley, P. (1988): «A Level History: On Historical Facts and Other Problems», Teaching History, 52, July, pp. 19-24.

Jenkins, K. y Munslow, A. (2004): The Nature of History Reader, Routledge, London.

KAYE, H. J. (1989): Los historiadores marxistas británicos, Prensas Universitarias de Zaragoza, Zaragoza.

Kellner, H. (1989): Language and Historical Representation: Getting the
Story Crooked, University of Wisconsin Press, Madison.

Korhonen, K. (2006): Tropes for the Past: Hayden White and the History/ Literature Debate, Rodopi, Amsterdam y New York.

LACAPRA, D. (2006): Historia en Tránsito. Experiencia, identidad, teoría crítica, FCE, Buenos Aires.

LyON MACFIE, A. (2009): «A possible (common-sense) defence of (my) history: A response to Keith Jenkins»,, Rethinking History, 13, 3 September, pp. 345-355.

Margolis, J. (2000): «Relativism and Interpretative Objectivity», en MARGOLIS, J. y RocKMORE, T. (eds.), The Philosophy of Interpretation, Blackwell, Oxford y Malden, pp. 200-226.

Mate, R. (2008): La herencia del olvido, Errata Naturae, Madrid.

Megill, A. (2007): Historical Knowledge, Historical Error: A Contemporary Guide to Practice, University of Chicago Press, Chicago.

Megill, A. (1989): "What Does the Term "Postmodern" Mean?», Annals of Scholarship, 6, pp. 129-151.

Megill, A. (1985): Prophets of Extremity: Nietzsche, Heidegger, Foucault, Derrida, University of California Press, Berkeley and Los Angeles.

Moore, A. y CAmpBell, E. (2001): From Hell, Planeta De Agostini, Barcelona.

Munslow, A. (2007): Narrative and History, Palgrave, Basingstoke y New York.

Munslow, A. (2003): The New History, Pearson, Essex.

Munslow, A. (2000): The Routledge Companion to Historical Studies, Routledge, London.

Munslow, A. (1997): Deconstructing History, Routledge, London.

Munslow, A. y Rosenstone, R. A. (2004): Experiments in Rethinking 
History, Routledge, London y New York.

Norris, CH. (2002): «Defending Derrida», The Philosophers' Magazine, 20, Autumn, pp. 41-43.

Novick, P. (2005): That Noble Dream. The "Objectivity Question» and the American Historical Profession, New York, Cambridge University Press.

OsBorne, P. (1996): A critical sense: interviews with intellectuals, Routledge, London y New York.

Osborne, P. (2005): How to read Marx, Granta, London.

PAul, H. (2011): «Performing History: How Historical Scholarship is Shaped by Epistemic Virtues», History and Theory, 50, pp. 1-19.

PAul, H. (2008): «A Weberian medievalist: Hayden White in the 1950s», Rethinking History, 12, 1, January, pp. 75-102.

Paul, H. (2006): Masks of Meaning. Existentialist Humanism in Hayden White's Philosophy of History, Rijksuniversiteit Groningen, Groningen.

Pinlainen, K. (1999): Resisting History. On the Ethics of Narrative Representation, University of Turku, Turku.

PRICE, R. (2002): First Time The Historical Vision of an African American People, University of Chicago Press, Chicago.

RORTY, R. (1999): Forjar nuestro país. El pensamiento de izquierdas en los Estados Unidos del siglo XX, Paidós, Barcelona.

RoRTY, R. (1991): Contingencia, ironía y solidaridad, Paidós, Barcelona.

RoRTY, R. (1982): Consequences of Pragmatism, University of Minnesota Press, Minneapolis.

Rosenstone, R. A. (2000): «A History of What Has Not Yet Happened», Rethinking History, 4, 2, pp. 183-192.

Rosenstone, R. A. (1996a): «Introduction», en Rosenstone, R. A. (ed.),
Revisioning History: film and the construction of a new past, Princeton University Press, Princeton, pp. 3-13.

Rosenstone, R. A. (1996b): Visions of The Past: Challenge of Film to Our Idea of History, Harvard University Press, Cambridge.

Roth, M. S. (2004): «Classic Postmodernism», History and Theory, 43, 3, October, pp. 372-378.

Schama, S. (1989): Citizens. A Chronicle of the French Revolution, Penguin, London.

Schama, S. (1993): Certezas Absolutas. Especulaciones sin garantía, Anagrama, Barcelona.

SteIner, G. (2006): En el castillo de Barba Azul, Gedisa, Barcelona.

TozzI, V. (2006): «La historia como promesa incumplida. Hayden White, heurística y realismo figural», Dianoia, LI, 57, pp. 103-130.

VAldés Miyares, R. (1999): «The Postmodern History Reader», Atlantis, 21, pp. 165-171.

VERGARA ANDERSON, L. (2001): «¿Un futuro sin historia? El debate entre Pérez Zagorin y Keith Jenkins (19992000)», Historia y Grafía, 28, abril.

VV.AA. (2009): «Rethinking Contextualism», Journal of the Philosophy of History, 3, 3.

VV.AA. (2003): Deconstrucción y Crítica, Siglo XXI, Madrid.

VAтtimo, G. (2004): Nihilismo y emancipación. Etica, Politica, Derecho, Paidós, Barcelona.

WALzer, M. (1998): Tratado sobre la tolerancia, Paidós, Barcelona.

White, H. (2010): The Fiction of Narrative. Essays on History, Literature and Theory, 1957-2007, The Johns Hopkins University Press, Baltimore.

White, H. (2009): «Foreword. The Postmodern messenger», en JENKINS, K. (2009a): At the Limits of History. 
Essays on Theory and Practice, Routledge, London.

White, H. (2003): El texto histórico como artefacto literario, Paidós/ICE/ UAB, Barcelona.

White, H. (1990): The Content of the Form, The Johns Hopkins University Press, Baltimore.
WINEBURG, S. (2001): Historical Thinking and Other Unnatural Acts: Charting the Future of Teaching the Past, Temple University Press, Philadelphia.

YeRXA, D. A. (2008): Recent Themes in Historical Thinking: Historians in Conversation, University of South Carolina, Columbia.

\section{NOTAS}

1 Gracias, en primer lugar, a las conversaciones y a los comentarios del profesor Keith Jenkins, quien me recibió en la Universidad de Chichester con los brazos abiertos y con una generosidad ilimitada. En segundo lugar, quiero agradecer a Vladimir López Alcañiz, Marisa González de Oleaga, Ernesto Bohoslavsky, Bárbara San Juan Sánchez y Arantxa Bolaños de Miguel por su apoyo y por su atenta y estimulante lectura.

2 Ankersmit, F. R.; Domaska, E. y Kellner, H. (2009)

3 La influencia de Ankersmit en la obra de Jenkins es indudable. Jenkins ha dedicado multitud de capítulos, artículos y reseñas a desentrañar lo más importante de la obra del filósofo holandés así como a destacar su aportación a la filosofía de la historia en las últimas décadas [uno de los últimos textos en: Jenkins (2006b)]. Sin embargo, progresivamente, Jenkins ha venido desencantándose de la postura conservadora y pesimista de la obra del profesor de Groningen. Para esto último, vid. Bolaños de Miguel (2009): 98; y Jenkins, K., "Cohen contra Ankersmit», copia particular, pp. 2 y 7, ahora publicado en Jenkins (2008b).

4 Jenkins (2006a): 193 y 221. Todas las traducciones del inglés son nuestras, excepto donde hay traducción al castellano, que citamos oportunamente.

5 Vid. Bertens (2002).

6 «Lo que el textualismo hace es prestar atención a las condiciones textuales bajo las cuales toda obra histórica es hecha, bajo las cuales todo conocimiento histórico es producido», en Jenkins (1996c): 85. Vid. también Jenkins (1992).

7 En este sentido, Hayden White afirma que la historia es construcción, «más específicamente un producto del discurso y la discursivización», en White (2003): 43.

8 Como ha mostrado Paul (2006). Le doy mis más sinceras gracias al profesor Herman Paul por facilitarme una copia de esta - su todavía inédita - tesis doctoral. El mismo White confirma esta conexión: Jenkins (1998): 72 y 74. Por otro lado, Paul está elaborando una interesante obra sobre las implicaciones epistemológicas de la práctica historiográfica: vid. Paul (2011).

9 Como recordó en un encuentro de la American Historical Association, en 1997, en la estela de Jacques Derrida o de Sande Cohen.

10 Una escueta pero muy competente introducción a White en: Jenkins (1994). Sobre el marxismo de Jenkins, vid. Jenkins (2008a): 72.

11 Domanska (2009). Sobre Danto, vid., entre otros, Ankersmit (2009).

12 A sus intenciones didácticas podemos añadir una preocupación pedagógica por los problemas de la enseñanza de la historia. Vid. un resumen de sus primeras propuestas en: Jenkins (1991); Jenkins, K. y Brickley, P. (1990); Jenkins (1985); y Jenkins (1986).

13 Debates mantenidos con, por ejemplo, Marnie Hughes, John Tosh, Arthur Marwick, Richard J. Evans, Michael Coleman o Pérez Zagorin. Vid. Jenkins (1996a). Vergara (2001) ha escrito una reseña titulada «¿Un futuro sin historia? El debate entre Pérez Zagorin y Keith Jenkins (1999-2000)». Otro de los autores con el que Jenkins ha «debatido» más, aunque sea post mortem, ha sido con el historiador inglés E. H. Carr: Jenkins (2000a).

14 Jenkins (1991a). Vid. una de las pocas reseñas sobre este libro, publicadas en España, en: Valdés Miyares (1999). Vid. también: González de Oleaga (2003).

15 Jenkins, K. y Munslow, A. (2004); Munslow (2000); Munslow (2003).

16 Jenkins (2003a): 1. Una perspectiva similar a la que se propone en este apartado en Lecker de Almeida, G., «Decoding Keith Jenkins' Postmodern History», copia privada.

17 Tal y como aparece en la obra de Hayden White o de Lyotard, por citar solamente dos influyentes autores.

18 Vid. Clark (2004).

19 Vid. Megill (1989); y Connor (1996).

20 Debemos distinguir entre «la postmodernidad» y «el postmodernismo», como fase cultural del capitalismo tardío (en la que vivimos) y como corriente (intelectual y artística) que es crítica de la modernidad y 
de la dinámica socio-política actual (postmodern critique), respectivamente, Jenkins (2009a): 11. Sin embargo, podemos utilizar indistintamente ambas palabras para referirnos a la obra de los autores estudiados en este trabajo.

21 Vid. Attridge (1997); Munslow (1997); y Rorty (1982).

22 Jenkins (2008a): 60; y Rorty (1991): 21-42, especialmente 26 y 41 .

23 Vattimo (2004): 47 y 117.

24 Precisamente porque esta liberación nos hace reflexionar, por ejemplo, sobre la memoria de los vencidos y de las víctimas de la historia, que han sido siempre olvidados por la historiografía. Vid. Mate (2008).

25 Domanska (2008): 15.

26 Jenkins (2006a): 171.

27 Godoy (1999).

28 Relativismo y anti-universalismo que ya se encontraban presentes en la crítica de la filosofía política occidental que supuso su tesis doctoral: Jenkins (1975): 2 y 6 .

29 Sin embargo, Norris sí ha defendido a Derrida de muchos de los detractores de la deconstrucción: Norris (2002)

30 Jenkins (2006a): 64.

31 «History is never for itself; it is always for someone», Jenkins (2003b): 21 [hay traducción al castellano, Jenkins (2009b)].

32 Jenkins (2003b): 7. Esta diferenciación entre el pasado y la historia - que nos avisa de la distancia entre ambos- es crucial tanto para la profesión como para los postmodernos. Sin embargo, los historiadores se esfuerzan por acortar esa distancia identificando, en muchos momentos, al uno con la otra. Vid. también: Jenkins (2003d): 2 y 3 .

33 Jenkins (2003b): 23

34 Jenkins (2003b): 77.

35 Kellner (1989): 12.

36 Cohen (1993): 62 y 152. Vid. también Davies (1989): 282

37 Jenkins (2003b): 67. Una respuesta a esta posición, en Lyon MacFie (2009).

38 Jenkins (2003b): 31-32; traducción en Jenkins (2009b): 34 .

39 En este punto, Jenkins recupera las reflexiones de Alain Badiou: Jenkins (2005): 17 y ss. Vid. también Jenkins, K. y Brickley, P. (1988).

40 Sobre la cuestión de la objetividad en la historiografía, vid. Novick (2005); y Haskell (1998).

$41 \mathrm{Vid}$. las sugerentes reflexiones de Jenkins sobre la empatía en: Jenkins, K. y Brickley, P. (1989). LaCapra también ha subrayado la importancia de la empatía en cualquier acercamiento al pasado: LaCapra (2006).

42 Jenkins (2009a): 238.

43 Jenkins (2006a): 32.

44 Jenkins (2006a): 184.

45 Jenkins (2003a): 49. Vid. la review de Roth (2004). Y Ankersmit (1983).
46 Munslow (2007): 15 y 17.

47 Jenkins (2006a): 33 y 34.

48 Jenkins diría representaciones «fallidas»: Jenkins (2003c).

49 Ankersmit (2006): 328. En este artículo, Ankersmit añade que tenemos a la escritura de la historia para compensar la ausencia del pasado ya que la representación significa, literalmente, hacer algo presente de nuevo -o traer algo al presente otra vez-.

50 Jenkins (2006a): 167.

51 Jenkins (2003a): 5, traducción nuestra.

52 La influencia de Sande Cohen en la obra de Jenkins es digna de tener en cuenta. Vid., por ejemplo, Cohen (1999) y Cohen (1993). Recientemente, Jenkins ha editado un número especial de la revista $R e-$ thinking History sobre la obra de Sande Cohen: vid. Jenkins (2008c).

53 Jenkins (2003b); Jenkins (1995); Jenkins (1997). Una excelente introducción (y resumen) a todas estas cuestiones, en: Jenkins (1996b).

54 Jenkins publicó varios artículos durante los años 1997-99 adelantando su postura «anti» historiográfica. Puede verse, por ejemplo, Jenkins (1997b). Un resumen de sus posturas post-Why History? en: Jenkins (2000b), donde el autor expone sus dos argumentos principales: que las formas de pensar postmodernas han problematizado la historia lower case - es decir, la historia con "minúsculas»- y que, probablemente, esas formas de pensar señalan el fin del «pasado-como-historia». Vid. también, sobre el fin de la historia: Jenkins (2002); y, por último, sobre este cambio en su obra, vid. Jenkins (2009a): 217.

55 Kellner (1989).

56 Megill (1985) y Megill (2007).

57 Rosenstone (1995); y Munslow, A. y Rosenstone, R. A. (2004).

58 Gumbrecht (2004); Gumbrecht (2005), y Gumbrecht (2006).

59 Schama (1993) y Schama (1989).

60 Jenkins (2004d): 134.

61 Jenkins (2006a): 160.

62 White (2009): 3; y Rosenstone (2000): 183

63 Jenkins (2006a): 27; Wineburg (2001): 6 y ss.; Yerxa (2008): 36; y Price (2002), gracias a Marisa González de Oleaga por esta referencia.

64 Jenkins (2006a): 335. La bibliografía sobre «otras formas» de historizar — o de relacionarse con el pasado - es muy abundante. La revista History and Theory ha publicado decenas de artículos sobre la materia.

65 Jenkins (2009a): 5.

66 Jenkins (2007b): 2 de la copia que me envió el profesor Jenkins. En la misma página, Jenkins se define como un "realista trascendentalista», trascendental realist, y, un poco más adelante, como un radical antirepresentationalist (p. 4). Ankersmit escribe que se puede ser positivista o empirista — en relación con la capacidad cognitiva de los enunciados-y, a la vez, tomarse muy en serio la teoría estética de la represen- 
tación al considerar el texto historiográfico como un todo, Ankersmit (2005): xiv. Vid., también, Jenkins (2008a): 61, donde Jenkins añade las características «idealista intersubjetivo» $\mathrm{y}$ «nominalista».

67 Jenkins (2006a): 23 y 132. Jenkins ha escrito que fueron Peter Brickley y Philip Jenkins quienes le convencieron de que el relativismo es la solución a los problemas de la existencia y de la moral. Con el primero de ellos, Jenkins ha escrito varios artículos que fueron publicados en la revista Teaching History. Vid. también: Jenkins (2007a): la tesis de este breve artículo es que el pasado puede ser leído o imaginado, por cualquiera, de cualquier forma que quiera. Vid. también Munslow (2000): 188.

68 Domanska (2008): 18; Jenkins (1995): 123; y Jenkins (2008a): 70 .

69 Desarrollado en textos como Jenkins (2009a): 255-269. Podemos encontrar más respuestas en Ankersmit (2001): 13-17, p. 22 y capítulo 2.

70 Jenkins (2006a): 273, entre muchas páginas. De Derrida, Jenkins también recupera su análisis acerca de los tres tipos de violencia en la producción de sentido.

71 Jenkins (2006a): 27; y Jenkins (2009a): 267.

72 Una excelente interpretación de la obra de Deleuze en Hallward (2006).

73 Jenkins (1999).

74 Salvo el propio Hayden White, vid. Paul (2008) y Jenkins (2009a): 16. Jenkins y Ankersmit estudiaron historia pero no se les puede considerar historiadores profesionales. De todas formas, Ankersmit ha despuntado en el campo de la historia intelectual y de la historia de la historiografía. Vid. una serie de entrevistas a algunas de estas personalidades, en Osborne (1996).

75 Jenkins (2005): 15; y Jenkins (2009a): 218.

76 Jenkins (2004a): 60. En Refiguring History —un texto de 2003 - y en algunos artículos de años inmediatamente anteriores y posteriores, Jenkins desarrolla su argumento radical sobre la innecesidad de la historiografía tradicional, académica y profesional e, incluso, sobre la innecesidad de cualquier tipo de historiografía, incluida la postmoderna. Para conocer las intenciones políticas que subyacen en la obra de Jenkins, vid. Jenkins (2003a): 5.

77 Deeds Ermarth (1992): 43; Jenkins (2006a): 288; vid. también Deeds Ermarth (2004).

78 Jenkins (2006a): 36.

79 Jenkins (2006a): 25, 35 y 37.

80 Jenkins (2009a): 12, traducción nuestra.

81 Como han subrayado Hayden White y Sande Cohen, entre otros.

82 Para todas estas cuestiones, vid. Breisach (2003).

83 Jenkins (2009a): 13.

84 Jenkins (2006a): 221.

85 Domanska (2008): 13. En este punto, es necesario mencionar la posición de Sande Cohen sobre la naturaleza desintelectiva de la historia académica y su marcada tendencia política conservadora. Vid. Cohen (2006): 260; y Cohen (1993): xxiii.
86 Kaye (1989): 224.

87 Como opina Ankersmit (2001): 15. Vid. Osborne (2005); y una comparación entre White y Jenkins, en Tozzi (2006): 122.

88 Citamos de las siguientes ediciones: Deeds Ermarth (1992) y Harlan (1997).

89 Jenkins (2006a): 267.

90 Otro aspecto no novedoso de la postmodernidad, ya que lo podemos encontrar en Spengler, por ejemplo. Deeds Ermarth (1992): 22; el tiempo, dice Ermarth, no es neutral ni absoluto sino que es una función de la posición, literalmente de la posición del lector. La temporalidad postmoderna hace a la misma temporalidad parte de un sistema de valores y de énfasis.

91 Vid. Deeds Ermarth (1998): 28; y Huehls (2009): 5 .

92 Sobre el contextualismo, vid. Jay (1993); y VV.AA. (2009).

93 Deeds Ermarth (1992): 14

94 Vid. Rosenstone (1996a).

95 Deeds Ermarth (1992): 14, 21, 46 ó 109.

96 Vid. González de Oleaga, M. y Bolaños de Miguel, A. M. (2008a) y González de Oleaga, M. y Bolaños de Miguel, A. M. (2008b).

97 Un experimento historiográfico postmoderno -impresionante por su documentación y deslumbrante por su imaginación - es la novela gráfica de Moore, A. y Campbell, E. (2001).

98 «Postmodernity offers new births», Jenkins (2003a): 70 .

99 Deeds Ermarth (1992): 23.

100 Jenkins (2006a): 280.

101 Domanska (2008): 18 y 19. Vid. también Pihlainen (1999): 9. La influencia de Nietzsche sobre la obra de Jenkins es fundamental. Su tesis doctoral versó sobre Ideology and Science in the Political Thought of F.W. Nietzsche, S. Freud and G. Sorel, 1975, copia privada facilitada por el autor. Vid. también: Jenkins (1982).

102 Jenkins (2009a): 17.

103 Harlan (1997): xvii y xix. Vid. Margolis, J., «Relativism and Interpretative Objectivity», en Margolis, J. y Rockmore, T. (2000).

104 Harlan (1997): xx.

105 Jenkins, K., «Disobedient Histories: The Irreverent Relevance of Future Pasts», copia privada, p. 23, traducción nuestra.

106 Deeds Ermarth (1992): 14.

107 Jenkins (2006a): 269.

108 Davies (2006) y Bolaños de Miguel (2007).

109 Vid., por ejemplo, Cohen (1996).

110 Jenkins (2003b): xiv.

111 Vid. Steiner (2006): 17. Sin embargo, el propio Steiner se pregunta al final del libro, «¿dónde está el programa de un modo de percepción humana que esté libre del "fetichismo" de la verdad abstracta?» (Ídem, 178).

112 Jenkins (2006a): 17; y Korhonen (2006). 
113 Jenkins (2009a): 7 y 8.

114 Vid., por ejemplo, Jenkins (2004b).

115 Jenkins (2006a): 333.

116 Ankersmit (2003): 417, donde Ankersmit subraya que lo que diferencia a los historiadores como Maquiavelo, Michelet o Ranke de nuestros contemporáneos es que los primeros comprendieron los problemas de la época y consideraron a la historia como el único instrumento para dar sentido a dichos problemas, con un sentimiento de urgencia que les falta a los segundos.

117 Jenkins (2006a): 334. Ni siquiera su estudio sobre la izquierda norteamericana es un texto «historizante» o con pretensiones descriptivas: es simplemente un intento provocador y presentista por resituar las ideas de la izquierda en la escena pública, conforme a su posición liberal y relativista, Rorty (1999).

118 Que tanta influencia ha tenido, incluso en la crítica literaria y cultural, tan cara al propio Derrida: vid., por ejemplo, VV.AA. (2003).

119 Sobre Lyotard, vid. Jenkins (2004c).

${ }^{120}$ Fish (1989).

121 Jenkins (2006a): 56 y 339: «ahora podemos vivir fuera de la historia pero en el tiempo, fuera de la ética pero en la moralidad, en formas emancipatorias mediante los imaginarios propuestos por la intelectualidad extraordinaria del pensamiento postmoderno», y Jenkins (2009a): 37.

122 Jenkins (2003b): 68; y White (1990): 227, nota 22. Sobre el relativismo de White, vid. Baghramian (2005): 86.

123 Vid. también White (2010): 61; y Connor (1996): 34 .

124 Badiou (2006): 23.

125 Jenkins (2009): 150, donde Jenkins habla de «disobedient histories».

126 Walzer (1998): 100.

127 Appleby, J.; Hunt, L. y Jacob, M. (1998): 15 y 23.

128 Derrida (1996): 4, nota 1.

129 Jenkins ha caracterizado, recientemente, a la «deconstrucción postmoderna» como «totalmente optimista», en el sentido nietzscheano del término, en Jenkins (2005): 25.

130 Algunas reflexiones en su última obra: Jenkins (2009a). La opinión de Cornel West sobre las relaciones entre una posición historicista, contextualista y, finalmente, revisionista, y una defensa de la libertad y de la democracia radical, es muy interesante, vid. Osborne (1996): 132. 